\title{
A novel monolithic column for capillary electrochromatographic separation of oligopeptides
}

\author{
Chun-Chi Lin, Guan-Ren Wang, Chuen-Ying Liu* \\ Department of Chemistry, National Taiwan University, 1, Sec. 4, Roosevelt Road, Taipei, Taiwan \\ Received 26 January 2006; received in revised form 8 May 2006; accepted 9 May 2006 \\ Available online 16 May 2006
}

\begin{abstract}
A monolithic column was prepared using L-phenylalanine as template and a covalent approach through the formation of Schiff base with $o$-phthalaldehyde (OPA). OPA, allylmercaptan, L-phenylalanine, and triethylamine were stirred at first, then methacrylic acid, 2-vinylpyridine, ethyleneglycol dimethacrylate, $\alpha, \alpha$-azobisisobutyronitrile, and 1-propanol were added to the reaction mixture. The resulting material was introduced into a capillary column. Following thermal polymerization, the template was then extracted with a mixture of $\mathrm{HCl}$ and methanol. The column was employed for the capillary electrochromatographic separation of oligopeptides. A capillary column of $75(50) \mathrm{cm} \times 75 \mu \mathrm{m}$ ID with a mobile phase of phosphate buffer $(\mathrm{pH} 7.0,40 \mathrm{mM}) /$ methanol $(5 \%, \mathrm{v} / \mathrm{v})$, an applied voltage of $+15 \mathrm{kV}$, and detection at $214 \mathrm{~nm}$, could baseline separate angiotensin I, angiotensin II, [Sar ${ }^{1}, \mathrm{Thr}^{8}$ ] angiotensin, oxytocin, vasopressin, tocinoic acid, $\beta$-casomorphin bovine, $\beta$-casomorphin human, and FMRF amide within $20 \mathrm{~min}$. The separation behavior of the templated polymer was also compared with that of the non-templated polymer. As a result, it can be concluded that the electrochromatographic separation of this set of peptides was mediated by a combination of electrophoretic migration and chromatographic retention involving hydrophobic, hydrogen bonding, electrostatic as well as the Schiff base formation with OPA in the cavity of the templated polymer.
\end{abstract}

(C) 2006 Elsevier B.V. All rights reserved.

Keywords: Monolithic column; Capillary electrochromatography; Oligopeptides

\section{Introduction}

Monolithic materials are becoming a well-established stationary phase format for capillary electrochromatography (CEC). Both the simplicity of their in situ preparation and the large number of readily available chemistries make monolithic separation columns an attractive alternative to the capillary columns packed with particulate materials [1-4]. The first example of a peptide separation by monolithic CEC appeared in 1997 by Palm and Novotny [5]. Their monolith was based on polyacrylamide/poly(ethylene glycol) with a $\mathrm{C} 12$ functionality. Five small peptides could be baseline separated within 5 min using isocratic elution.

Molecularly imprinted polymers (MIPs) have become an increasingly active field of study for the construction of new materials capable of molecular recognition in the field of analytical chemistry [6-10]. Usually, only low molecular weight

\footnotetext{
* Corresponding author. Tel.: +886 2 33661645; fax: +886223638543.

E-mail address: cyliu@ntu.edu.tw (C.-Y. Liu).
}

compounds are used as templates. The reason for this is that at least two effects steric and thermodynamic, have been reported to hinder the synthesis of MIPs selective to macromolecules such as proteins [11]. Preparation of a MIP can be divided into three categories: covalent, non-covalent, and sacrificial spacer methodologies [12]. Template molecule can either be the analyte of interest or a structural analogue. Most work has involved the non-covalent approach. The covalent approach is more difficult to apply, because it requires multiple heteroatom functionality to be available in the template molecule. Hence, examples that use this approach are relatively rare in the literature [13-15]. In addition, most MIPs have been prepared in a nonaqueous solvent, and it is a challenge to prepare a MIP containing a water-soluble template $[16,17]$.

Peptide separations by the MIP method with HPLC have been described in several publications [18-27]. Rachkov and Minoura [23] proposed the epitope approach for the separation of peptides and proteins. This method was based on using a short peptide that represents only part of a larger peptide or protein for the preparation of the MIP. Although other parts of peptides can 
influence the process of molecular recognition, the polymers imprinted with a short peptide efficiently recognize both the template and larger peptides.

Unger et al. [28] recently reviewed the current state of peptide separation by CEC. The use of monolithic materials is becoming a popular stationary phase for CEC [29,30]. OPA is a very popular analytical reagent. Recently, Lin and Liu [31] used OPA in borate buffer for the CEC separation of amino acids by oncolumn derivatization. Subrahmanyam et al. [32] developed a MIP sensor based on an OPA derivative. The measurements were carried out with particle size of 1-5 $\mu \mathrm{m}$ MIP [33]. The phenylalanine anilide MIP was found to be enantioselective in supercritical fluid chromatography with strong retention for the template enantiomer [34]. In the present work, an amino acid with aromatic side chain, phenyalanine was used as the template, and covalent approach to templating was used by preparation of a monolithic column in situ through the formation of Schiff base with OPA to evaluate the potential for the CEC separation of certain oligopeptides that have important medical uses.

\section{Experimental}

\subsection{Apparatus}

All experiments were carried out in a laboratory-built unit. It consisted of a $\pm 30 \mathrm{kV}$ high voltage power supply (Gamma High Voltage Research Inc., Ormond Beach, FL, USA) and a UV-vis detector (Spectra System UV3000, Thermo Separation Products, CA, USA). Electrochromatograms were recorded and processed with a TSP ChromQuest (Thermo Separation Products, CA, USA) and PC SISC-Lab (32) data acquisition system (Scientific Information Service Co., Taiwan). Fused silica capillaries (Polymicro Technologies, Phoenix, AZ, USA) were of $75 \mu \mathrm{m}$ ID and the total length of the capillary was $75 \mathrm{~cm}$, with a distance of $50 \mathrm{~cm}$ between the injection end and the detection window.

\subsection{Reagents and chemicals}

Most chemicals were analytical reagent grade from Merck (Darmstadt, Germany). Purified water $(18 \mathrm{M} \Omega \mathrm{cm})$ from a Milli$\mathrm{Q}$ water purification system (Millipore, Bedford, MA, USA) was used to prepare all solutions. The oligopeptides of synthetic grade, including FMRF amide, $\beta$-casomorphin bovine Fragment $1-5$ hydrochloride ( $\beta$-Casom $B$ ), human $\beta$-casomorphin acetate salt ( $\beta$-Casom $H)$, human angiotensin $I$ acetate salt (Ang-I), human angiotensin II acetate salt (Ang-II), [Sar ${ }^{1}$, $\mathrm{Thr}^{8}$ ] angiotensin II acetate salt (Ang-ST), oxytocin acetate salt (OT), [deamino-Cys ${ }^{1}, \mathrm{D}^{-\mathrm{Arg}^{8}}{ }^{\mathrm{C}}$-vasopressin acetate salt (Vas), and tocinoic acid (Toc) were obtained from Sigma (St. Louis, MO, USA). The following were purchased from the indicated sources: phosphoric acid, sodium phosphate monobasic, dibasic and tribasic, $d$-chloroform (Merck); $\alpha, \alpha$-azobisisobutyronitrile (AIBN) and triethylamine (TEA) (Wako, Japan); methanol, $o$ phthalaldehyde (OPA), ethyleneglycol dimethacrylate (EDMA), 2-vinylpyridine (2-VPY), and 1-propanol (Acros, Geel, Belgium); methacrylic acid (MAA) (Lancaster, Lancashire, UK); allyl mercaptan (AM) and 3-trimethoxysilylpropyl methacrylate ( $\gamma$-MPS) (TCI, Tokyo, Japan); and mesityl oxide (Perak, Berlin, Germany).

Stock solutions of the oligopeptides $\left(2.5 \mathrm{mg} \mathrm{ml}^{-1}\right)$ except $\beta$ Casom B, OT and Vas $\left(0.5 \mathrm{mg} \mathrm{ml}^{-1}\right)$ were prepared in pure water and diluted appropriately prior to use. All solvents and solutions for CEC analysis were filtered through a $0.45 \mu \mathrm{m}$ PTFE (Millipore, Bedford, MA, USA) or cellulose acetate membrane (Whatman, St. Louis, MO, USA).

\subsection{Silanization of the capillary column [35]}

Fused silica capillaries were first flushed with $1 \mathrm{M} \mathrm{NaOH}$ (30 $\mathrm{min})$, then pure water $(15 \mathrm{~min}), 1 \mathrm{M} \mathrm{HCl}(30 \mathrm{~min})$ and pure water $(15 \mathrm{~min})$. Before silanization, the capillaries were rinsed with methanol ( $5 \mathrm{~min}$ ) and then dried in a gas chromatography oven at $110^{\circ} \mathrm{C}$ for $4 \mathrm{~h}$ under a nitrogen flow of $2.5 \mathrm{~kg} \mathrm{~m}^{-1} \mathrm{~s}^{-2}$. For in situ polymerization, the capillary wall was first functionalized by filling with $\gamma$-MPS $(40 \mathrm{mg})$ in $0.1 \%$ TEA/toluene $(1 \mathrm{ml})$, then plugged with GC septa and reacted at $110^{\circ} \mathrm{C}$ for $12 \mathrm{~h}$. The silylated capillary was rinsed with toluene to remove unreacted material.

\subsection{In situ polymerization and functionalization}

Methanol (10 ml), OPA (271 mg; ca. $2.0 \mathrm{mmol})$, AM (164 mg; ca. $2.0 \mathrm{mmol})$, L-phenylalanine $(335 \mathrm{mg}$; ca. $2.0 \mathrm{mmol})$, and TEA $(13 \mathrm{mg}$; ca. $0.1 \mathrm{mmol})$ as catalyst were added to the round-bottom flask $(50 \mathrm{ml})$ and reacted with stirring at ambient temperature for $12 \mathrm{~h}$. Unreacted residue was removed by filtration. Then MAA (16 mmol), 2-VPY (16 mmol), EDMA (78 mmol), AIBN (123 mg), and 1-propanol $(30 \mathrm{ml})$ were added to the filtrate. After the mixture was completely dissolved under ultrasonication at a temperature lower than $10^{\circ} \mathrm{C}$, it was introduced into the silylated capillary column. The filling step was allowed to continue for $10 \mathrm{~min}$. The capillaries were then again plugged with GC septa and the polymerization was initiated thermally by placing the capillary under $\mathrm{GC}$ oven at $100{ }^{\circ} \mathrm{C}$ for $25 \mathrm{~min}$. The corresponding blank polymer was synthesized analogously to the respective monolithic polymer but in the absence of template molecules.

\subsection{Template removal}

Thereafter, the stationary phase was washed by perfusing the column with acetone for 30 min under a nitrogen flow of $2.5 \mathrm{~kg} \mathrm{~m}^{-1} \mathrm{~s}^{-2}$ and then washed with $\mathrm{HCl}(10 \mathrm{mM}$ in $50 \%$ $\mathrm{MeOH}$ ) for $20 \mathrm{~min}$. The resulting column was washed with pure water for $20 \mathrm{~min}$.

\subsection{Capillary electrochromatographic conditions}

Before analysis, the monolithic columns were preconditioned with the running buffer. They were rinsed with methanol, pure water, and buffer between runs at 1 or 2 min intervals. The samples were injected by siphoning at a height difference of $10 \mathrm{~cm}$ for $10 \mathrm{~s}$. Electroosmotic flow (EOF) was measured with mesityl 
oxide. The samples were detected by UV light absorption measurement at $214 \mathrm{~nm}$, and the detection was performed through the monolith polymer.

\section{Results and discussion}

Fig. 1 displays the preparation of the OPA basis of molecularly imprinted polymer. In general, the interaction of MIP toward the analyte is favored in the nonaqueous solvent. But the template-phenylalanine is water soluble and its OPA derivativeisoindole is light sensitive. The synthetic procedure was therefore carried out in methanol in the dark. TEA was added to catalyze the derivative reaction. After this procedure, only filtration was needed to yield the pure OPA derivative.

For having a greater interaction force between analyte and the monolith polymer, both MAA and 2-VPY were selected as the functional monomers. The $\mathrm{p} K_{\mathrm{a}}$ values for MAA and 2-VPY are
5.4 [36] and 4.95 [37], respectively. Under acidic conditions the prepared monolith polymer can act as an anion exchanger, while in the basic condition it can act as the cation exchanger. When a voltage was applied and the buffer solution was introduced into the column, cationic and anodic EOF would be originated, depending on the acidity of the medium. In other words, a mixed mode separation mechanism would be expected, besides the molecular recognition stemmed from the cavity of phenylalanine.

The peptides chosen in this work can be classified in four categories: (A) Angiotensin: Ang-I is a 10 residue peptide, Ang-II is an eight residue peptide, Ang-ST is a derivative of Ang II. (B) Opioid neuropeptides: $\beta$-Casom B and $\beta$-Casom H. (C) OT and Vas are neurohypophyseal hormones, Toc is an oxytocin inhibitor. (D) FMRF amide is a neuropeptide. All contained either Phe or Tyr or both residues. The sequence of these peptides is indicated in Table 1.<smiles>c1ccc2ccccc2c1</smiles><smiles>C=CCS</smiles><smiles>C=CCSC(O)c1ccccc1C=O</smiles><smiles>C=CCSC(O)c1ccccc1C=O</smiles><smiles>NC(Cc1ccccc1)C(=O)O</smiles><smiles>CCC</smiles><smiles>C=CCSc1c2ccccc2cn1C(Cc1ccccc1)C(=O)O</smiles>

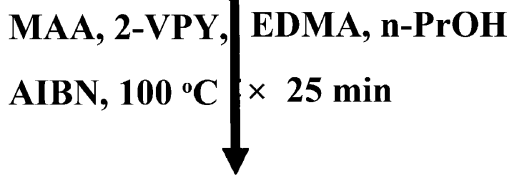<smiles>CC(CC(C)(C)C)C(=O)OC(O)c1ccccc1C(=O)O</smiles>

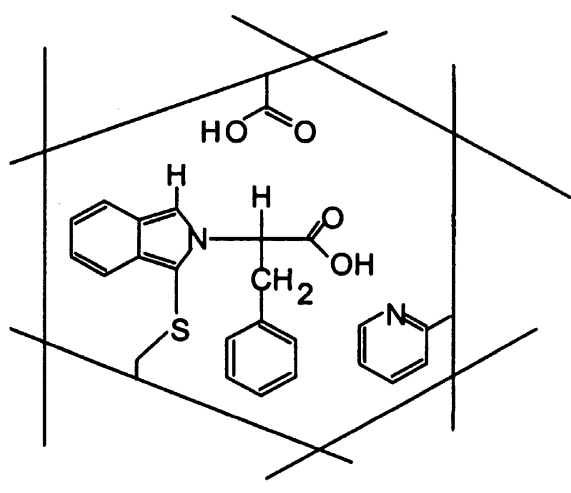

Fig. 1. Preparation of the $o$-phthalaldehyde basis of templated polymer. 
Table 1

Amino acid sequences of the analytes

\begin{tabular}{|c|c|c|}
\hline Peptides (MW) & $\mathrm{p} I(\text { calc. })^{\mathrm{a}}$ & Sequence \\
\hline FMRF (598.76) & 12.48 & Phe-Met-Arg-Phe-NH 2 \\
\hline OT (1007.19) & 10.17 & $\begin{array}{l}\text { Cys-Tyr-Ile-Gln-Asn-Cys-Pro-Leu- } \\
\text { Gly-NH } \mathrm{NH}_{2} \text { (disulfide bridge: } 1-6 \text { ) }\end{array}$ \\
\hline Ang-ST (956.10) & 9.85 & Sar-Arg-Val-Tyr-Ile-His-Pro-Thr \\
\hline Vas $(1069.22)$ & 11.28 & $\begin{array}{l}\text { DeaminoCys-Tyr-Phe-Gln-Asn-Cys- } \\
\text { Pro-Arg-Gly- } \mathrm{NH}_{2} \text { (disulfide bridge: } \\
\text { 1-6) }\end{array}$ \\
\hline Ang-I (1296.49) & 7.91 & $\begin{array}{l}\text { Asp-Arg-Val-Tyr-Ile-His-Pro-Phe- } \\
\text { His-Leu }\end{array}$ \\
\hline Ang-II (1046.19) & 7.76 & Asp-Arg-Val-Tyr-Ile-His-Pro-Phe \\
\hline$\beta$-Casom B (579.65) & 5.93 & Tyr-Pro-Phe-Pro-Gly \\
\hline Toc $(740.85)$ & 6.02 & $\begin{array}{l}\text { Cys-Tyr-Ile-Gln-Asn-Cys (disulfide } \\
\text { bridge: } 1-6 \text { ) }\end{array}$ \\
\hline$\beta$-Casom H (864.01) & 3.30 & Tyr-Pro-Phe-Val-Glu-Pro-Ile \\
\hline
\end{tabular}

a http://www.embl-heidelberg.de/cgi/pi-wrapper.pI. Reference from A.L. Lehninger, Biochimie, Worth Publishers, New York, 1979.

\subsection{Effect of $p H$ of the mobile phase}

The EOF velocity was monitored with mesityl oxide. Since the monolithic column bears MAA and 2-VPY, the anodic EOF would change into a cathodic EOF at $\mathrm{pH}$ values above 7 . In phosphate buffer $(20 \mathrm{mM})$ and applied voltage of $+15 \mathrm{kV}$, the EOF was over the range from 3.51 to $4.82 \times 10^{-4} \mathrm{~cm}^{2} \mathrm{~V}^{-1} \mathrm{~s}^{-1}$ as the $\mathrm{pH}$ changed from 5 to 8 . Meanwhile, only a cathodic EOF was observed throughout the $\mathrm{pH}$ range studied. Here, OPA-Phe adduct was used as template, and after polymerization, phenylalanine was extracted with a mixture of $\mathrm{HCl}$ and methanol. The remaining was OPA-hemiacetal adduct, and no additional carboxylic group. So the EOF was mainly from the protonated 2VPY $\left(\mathrm{p} K_{\mathrm{a}} 4.95\right)$ and the ionized MAA $\left(\mathrm{p} K_{\mathrm{a}} 5.4\right)$. But we cannot ignore the contribution from the residual silanol groups.

With phosphate buffer $(20 \mathrm{mM})$ as mobile phase and an applied voltage of $+15 \mathrm{kV}$, increasing the $\mathrm{pH}$ led to a progressive increase of the retention of all analytes (Fig. 2). The dependence on $\mathrm{pH}$ can be compared with the behavior of the neutral marker (Fig. 3). Analytes with retention times shorter than that of mesityl oxide indicate that they carry the positive charge, while those with retention times longer than that of mesityl oxide might carry the negative charge. At $\mathrm{pH} 5$, FMRF has two protonated amino groups; one is on the N-terminal and the other is on the side chain of arginine, so the mobility is the highest among the analytes. By taking into account the $\mathrm{p} K_{\mathrm{a}}$ values of MAA (5.4) and 2-VPY (4.95), there should have a small net positive charge of the stationary phase at $\mathrm{pH} 5$. In other words, the interaction force between analytes and the stationary phase is rather weak. The retention more or less might be due to hydrogen bonding, hydrophobic interaction or the partitioning between mobile and stationary phases besides the electrophoretic mobility. Here, the pairs of Vas and Ang-I as well as Ang-II and $\beta$-Casom B were coeluted at $\mathrm{pH} 5$ and 6 . On increasing the $\mathrm{pH}$ to 7 , the resolution of Ang-II and $\beta$-Casom B was improved significantly, but at $\mathrm{pH}$ 8 some overlap for $\beta$-Casom B and Toc was shown. The separation condition was set at $\mathrm{pH} 7$ for the further work, although Ang-I and Ang-II were not baseline separated.
(A) $\mathrm{pH} 5.0$ I $5 \mathrm{mAU}$

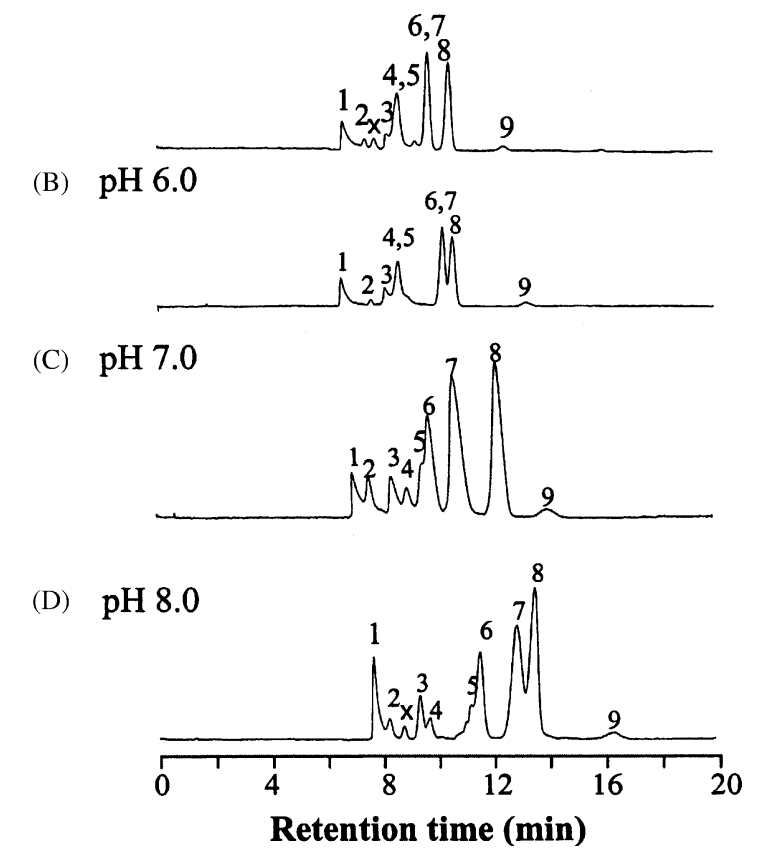

Fig. 2. Electrochromatograms of oligopeptides at various $\mathrm{pHs}$ of phosphate buffer. Column: monolith with phenylalanine as template, $75 \mathrm{~cm}(50 \mathrm{~cm}$ to the detector $) \times 75 \mu \mathrm{m}$; injection mode: hydrostatic $(10 \mathrm{~cm}, 10 \mathrm{~s})$; mobile phase: phosphate buffer $(20 \mathrm{mM})$; applied voltage: $+15 \mathrm{kV}$; detection: $214 \mathrm{~nm}$. Peak identification: (1) FMRF, (2) OT, (3) Ang-ST, (4) Vas, (5) Ang-I, (6) Ang-II, (7) $\beta$-Casom B, (8) Toc, (9) $\beta$-Casom $H$ (note: $\times$ indicates impurity).

\subsection{Effect of the concentration of the mobile phase}

Fig. 4 displays the effect of buffer concentration on the separation. At $20 \mathrm{mM}$ phosphate buffer, Ang-I and Ang-II were

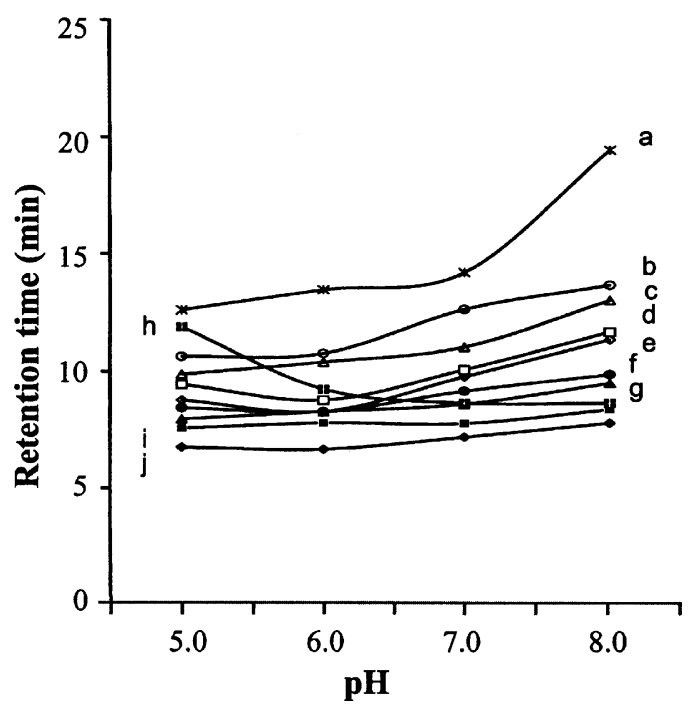

Fig. 3. Retention time vs. pH for the oligopeptides on templated column. Column: monolith with phenylalanine as template, $75 \mathrm{~cm}(50 \mathrm{~cm}$ to the detector) $\times 75 \mu \mathrm{m}$; injection mode: hydrostatic $(10 \mathrm{~cm}, 10 \mathrm{~s})$; mobile phase: phosphate buffer $(20 \mathrm{mM})$; applied voltage: $+15 \mathrm{kV}$; detection: $214 \mathrm{~nm}$. (a) $\beta$-Casom H, (b) Toc, (c) $\beta$-Casom B, (d) Ang-II, (e) Ang-I, (f) Vas, (g) Ang-ST, (h) mesityl oxide, (i) OT, (j) FMRF. 
(A) $60 \mathrm{mM}$

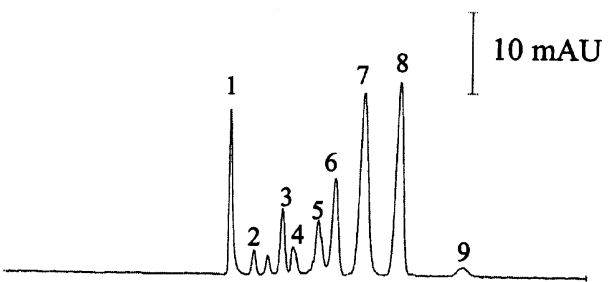

(B) $40 \mathrm{mM}$

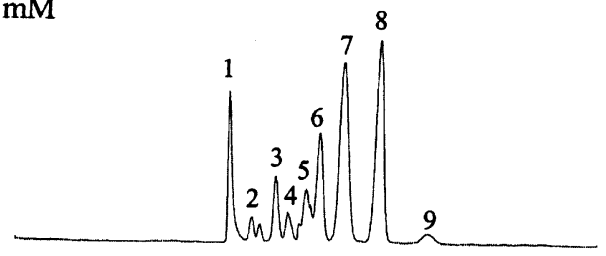

(C) $20 \mathrm{mM}$

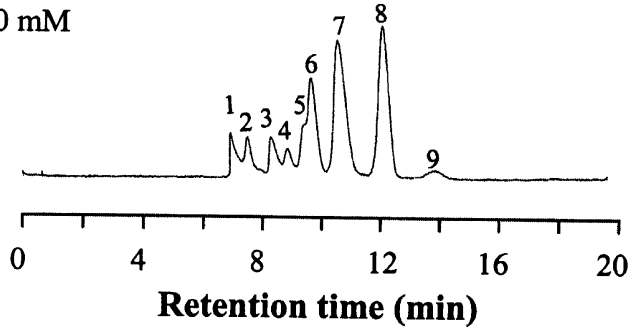

Fig. 4. Electrochromatograms of oligopeptides in different concentrations of phosphate buffer ( $\mathrm{pH}$ 7.0). Column: monolith with phenylalanine as template, $75 \mathrm{~cm}(50 \mathrm{~cm}$ to the detector $) \times 75 \mu \mathrm{m}$; injection mode: hydrostatic $(10 \mathrm{~cm}$, $10 \mathrm{~s}$ ); applied voltage: $+15 \mathrm{kV}$; detection: $214 \mathrm{~nm}$. Peak identification: (1) FMRF, (2) OT, (3) Ang-ST, (4) Vas, (5) Ang-I, (6) Ang-II, (7) $\beta$-Casom B, (8) Toc, (9) $\beta$-Casom $\mathrm{H}$.

coeluted. Increase ionic strength would result in a less retention for the MIP column. On the contrary, the EOF tends to decrease at higher ionic strength. The overall result in a slightly longer retention time and better resolution as the buffer concentration increased. However, the current increased to $60 \mu \mathrm{A}$ at $60 \mathrm{mM}$ phosphate buffer. Under these conditions, air bubbles formed easily due to Joule heating. Hence $40 \mathrm{mM}$ was selected for further work.

\subsection{Effect of composition of the mobile phase}

To get an insight into the nature of the interactions, we investigated the influence of the composition of the mobile phase. By variation the amount (5-20\%) of additive at phosphate buffer $(\mathrm{pH} 7.0,40 \mathrm{mM})$, it was found that the EOF decreased in the following order: acetonitrile $>$ methanol $>$ ethanol $>1$-propanol (Fig. 5). At low percentage $(<10 \%)$ of these additives, we found almost no difference for the peak shape among them and only found differences in the retention time (Fig. 6). Decreasing the water content of the mobile phase, might lead to better resolution of the analyte. But as the concentrations of 1-propanol and methanol were further increased to $20 \%$, peak-broadening and much lower peak height were exhibited. Eventually, it was found that a mobile phase of phosphate buffer $(\mathrm{pH} 7.0$,

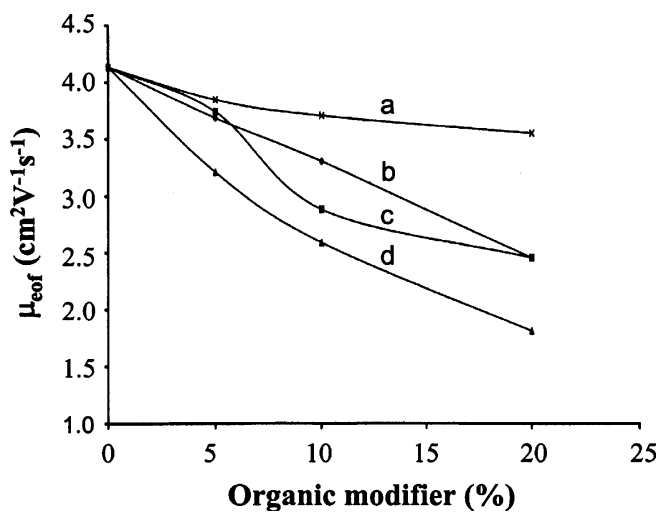

Fig. 5. Electroosmotic flow mobility vs. percentage of organic modifier. Column: monolith with phenylalanine as template, $75 \mathrm{~cm}(50 \mathrm{~cm}$ to the detector) $\times 75 \mu \mathrm{m}$; injection mode: hydrostatic $(10 \mathrm{~cm}, 10 \mathrm{~s})$; applied voltage: $+15 \mathrm{kV}$; detection: $214 \mathrm{~nm}$. Neutral marker: mesityl oxide. Mobile phase: phosphate

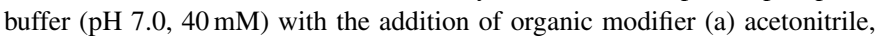
(b) methanol, (c) ethanol, (d) 1-propanol.

$40 \mathrm{mM}) /$ methanol (5\%, v/v) mixture offered the best comprise between resolution and analysis time.

\subsection{Separation mechanism}

In this work, the templated polymer was prepared based on the formation of an OPA derivative. Reduced peak heights and poor resolution were found at $\mathrm{pH}$ values higher than 9 ; however, slightly less basic conditions ( $\mathrm{pH}$ 6-8) were advantageous for the Schiff base formation. One of the reasons might be due to less affinity between them at more basic condition. Subrahmanyam et al. [32] also stated that there are some distortion for the binding sites between creatine and functional groups in the polymer at higher $\mathrm{pH}$. The phenomenon is probably a result of ionization processes or hydroxyl anion interference in the recognition process.

The retention time of the mesityl oxide was decreased as the $\mathrm{pH}$ increase, and levels off at $\mathrm{pH} 7$ and 8 (Fig. 3). The constant EOF can be explained by the presence of free base (2-VPY) and fully ionized MAA. At $\mathrm{pH} 5$, only $\beta$-Casom $\mathrm{H}$ carries a negative charge (Fig. 3). Because it tends to migrate against EOF, it was eluted last. According to the $\mathrm{p} I$ values (Table 1), the elution order should be FMRF $>$ Vas $>$ OT $>$ AngST $>$ Ang-I $>$ Ang-II $>$ Toc $>\beta$-Casom $\mathrm{B}>\beta$-Casom $\mathrm{H}$ under the experimental conditions ( $\mathrm{pH} 5-8$ ), this outcome was not exactly as expected.

Oxytocin is a nonapeptide. The formation of a disulfide bond between the Cys residues at positions 1 and 6 results in a peptide consisting of a 6-amino acid cyclic portion and a 3-amino acid C-terminus. The structure of Vas is similar to that of OT, except that Phe and Arg replace Ile and Leu. The retention was stronger than that of OT, which might be the result of the presence of template molecule-phenylalanine in the peptide sequence, although it is not in the $\mathrm{N}$-terminal sequence. In comparison with the retention behavior of the linear peptides: Ang-I, Ang-II, AngST, $\beta$-Casom B and $\beta$-Casom $H$, cyclic peptides were eluted earlier because of steric hindrance with the exception of Toc, which lacks the side chain. 
ACN

a. $0 \%$

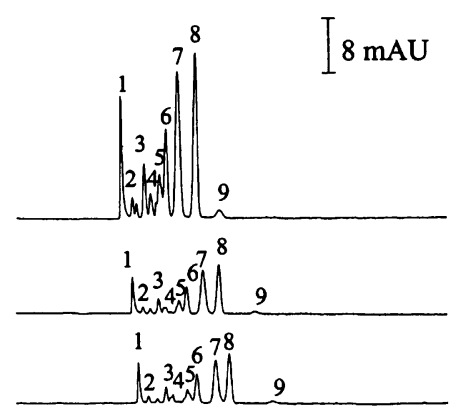

c. $10 \%$

d. $20 \%$

(A)

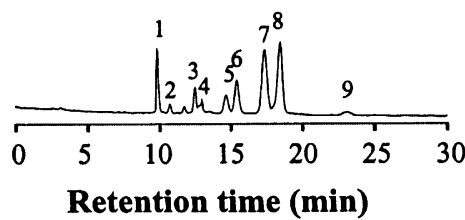

$\mathrm{MeOH}$ a. $0 \%$

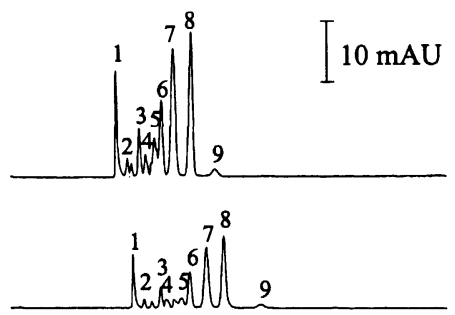

c. $10 \%$

d. $20 \%$

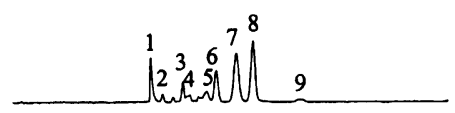

(B)

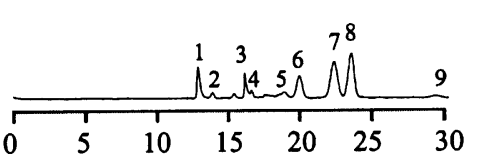

Retention time (min)
EtOH

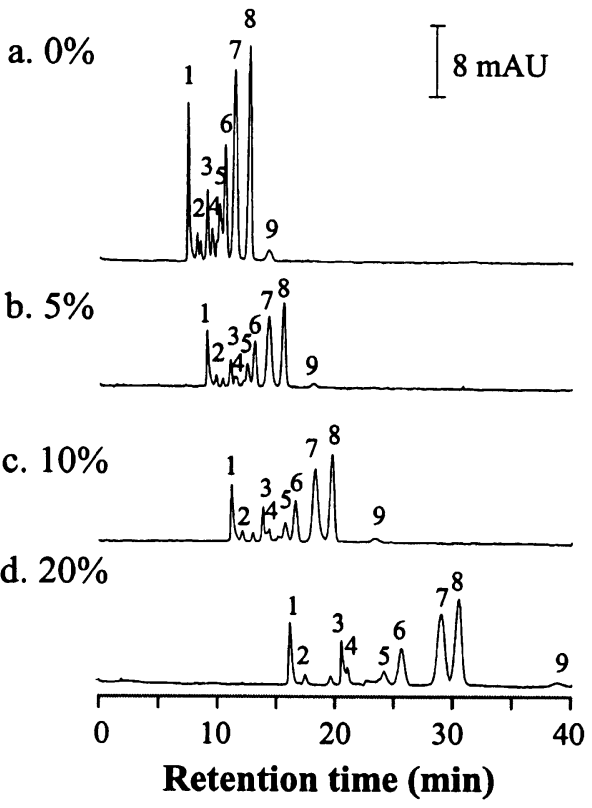

PrOH

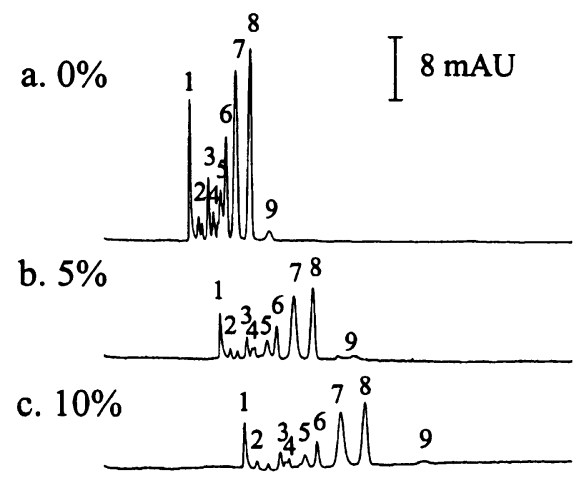

d. $20 \%$

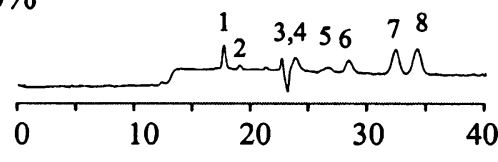

Retention time (min)

Fig. 6. Electrochromatograms of oligopeptides in phosphate buffer with different amount of organic additives. Conditions as Fig. 2 except phosphate buffer (pH 7.0, $40 \mathrm{mM}$ ) with organic additive. Peak identification: (1) FMRF, (2) OT, (3) Ang-ST, (4) Vas, (5) Ang-I, (6) Ang-II, (7) $\beta$-Casom B, (8) Toc, (9) $\beta$-Casom H.

Among the angiotensin series, Ang-I has two more amino acids than Ang-II. Different affinity with the stationary phase can be seen due to the steric hindrance. Ang-ST has a methylated sarcosine and threonine at positions 1 and 8 in the sequence compared with those of Ang-II. Less hydrogen bonding and hydrophobic force toward the monolith polymer than Ang-II would be. Hence Ang-ST was eluted earlier than Ang-I and Ang-II. By further considering their $\mathrm{p} I$ values, there are large difference for the net charge between Ang-I and Ang-II at pH 5 and 6 than that at $\mathrm{pH} 7$ and 8. So a better resolution was found at the lower pH (Fig. 2).

Fig. 5 shows the plotting of $\mu_{\text {eo }}$ versus percentage of organic modifier. The EOF velocity depends on the density of charge on the polymer matrix as well as the properties of the electrolyte.
The magnitude of the EOF is proportional to the permittivity of the solution and the zeta potential of the material, and inversely proportional to the dynamic viscosity of the solution. With the addition of organic solvent, the EOF decreases in the order: acetonitrile $>$ methanol $>$ ethanol $>$ 1-propanol. Hence the retention time is least with acetonitrile as modifier, while that is longest with 1-propanol as additive. Since less amount of aqueous buffer is favored for the hydrogen bond formation between analytes and the monolith polymer, more additive in the mobile phase would result in a stronger interaction between them. Therefore longer retention time and smaller peak intensities were indicated especially for 1-propanol. The other reason for the smaller peak intensities might be due to the variation of extinction coefficient (Beer's law) at different solvent system. 

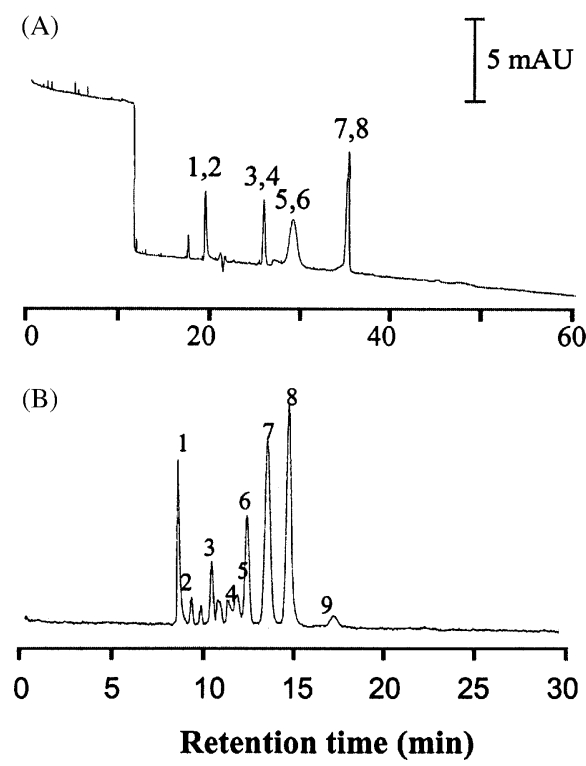

Fig. 7. Comparison the electrochromatograms of templated column with that of non-templated one for the separation of oligopeptides. Conditions as Fig. 2

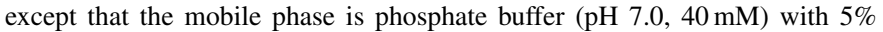
methanol. Monolithic column: (A) Non-templated, (B) templated. Peak identification: (1) FMRF, (2) OT, (3) Ang-ST, (4) Vas, (5) Ang-I, (6) Ang-II, (7) $\beta$-Casom B, (8) Toc, (9) $\beta$-Casom H.

\subsection{Comparison of the retention behavior of templated with that of non-templated monolith (blank polymer)}

Selectivity of the templated monolith was further assessed by comparing with the blank polymer under similar experimental conditions (Fig. 7). Longer retention time but poorer resolution for the analytes in blank polymer was observed. This may be attributed to more OPA being exposed on the surface or randomly distributed in the blank polymer. The nonspecific binding sites could bind all kinds of amino acids but no cavity limitation for the molecular recognition. More specific sites should exist in the templated column although heterogeneity binding sites can also be found.

\subsection{Column performance}

The separation efficiencies of the column at phosphate buffer $(\mathrm{pH} 7.0,40 \mathrm{mM}) /$ methanol $(5 \%, \mathrm{v} / \mathrm{v})$, an applied voltage of $+15 \mathrm{kV}$ and detection at $214 \mathrm{~nm}$, for the analytes were over the range from 8000 to 21,000 plates $/ \mathrm{m}$. The relative standard deviations (R.S.D.s) of retention time $(\mathrm{min})$ for the analytes were in the range of $0.81-5.84 \%$ based on the ion with the largest electrophoretic mobility as the reference. The data were the average of five measurements.

\section{Conclusions}

Proteins are not only the building blocks for organisms; they also play many other important roles in biological systems. Consequently, the separation of peptides and proteins becomes increasingly important as scientists work to characterize pro- teins and their digests. This work provides a template imprinting technology for the preparation of a novel monolithic column. Although the analytes chosen did not correspond to that of the template, the templated column indeed can create different types of selectivity. The separations might be mediated by a combination of electrophoretic migration and chromatographic retention involving hydrophobic, hydrogen bonding, $\pi-\pi$ interaction, electrostatic as well as the Schiff base formation with OPA in the cavity of the templated polymer. Conventionally, a broadened peak due to stronger interaction with the binding site is shown for the MIP column. Here a sharper peak was found. Additionally, the column could be employed for the separation of a wide range of analytes. Here we must mention, both basic amino acid-arginine and acidic amino acid-aspartic acid have also been tested as the template for this separation. But the results indicated the aromatic amino acid-phenylalanine give the best results.

\section{Acknowledgement}

The authors thank the National Science Council of Taiwan for financial support.

\section{References}

[1] V. Kašička, Electrophoresis 24 (2003) 4013.

[2] Y. Li, R. Xiang, J.A. Wilkins, C. Horváth, Electrphoresis 25 (2004) 2242.

[3] D. Bandilla, C.D. Skinner, J. Chromatogr. A 1044 (2004) 113.

[4] K. Hutterer, V. Dolník, Electrophoresis 24 (2003) 3998.

[5] A. Palm, M.V. Novotny, Anal. Chem. 69 (1997) 4499.

[6] P. Spégel, L. Schweitz, S. Nilsson, Electrophoresis 24 (2003) 3892.

[7] L.I. Andersson, J. Chromatogr. B 745 (2000) 3.

[8] K. Haupt, Analyst 126 (2001) 747.

[9] C.Y. Liu, C.C. Lin, Electrophoresis 25 (2004) 3997.

[10] G. Gübitz, M.G. Schmid, Electrophoresis 25 (2004) 3981.

[11] F. Flam, Science 263 (1994) 1221

[12] M.J. Whitcombe, E.N. Vulfson, Adv. Mater. 13 (2001) 467.

[13] T. Ikegami, T. Mukawa, H. Nariai, T. Takeuchi, Anal. Chim. Acta 504 (2004) 131.

[14] T. Mukawa, T. Goto, T. Takeuchi, Analyst 127 (2002) 1407.

[15] M.A. Khasawneh, P.T. Vallano, V.T. Remcho, J. Chromatogr. A 922 (2001) 87.

[16] B.R. Hart, K.J. Shea, Macromolecules 35 (2002) 6192.

[17] E. Piletska, S. Piletsky, K. Karim, E. Terpetschnig, A. Turner, Anal. Chim. Acta 504 (2004) 179.

[18] G. Theodoridis, G. Konsta, C. Bagia, J. Chromatogr. B 804 (2004) 43.

[19] A. Rachkov, M. Hu, E. Bulgarevich, T. Matsumoto, N. Minoura, Anal. Chim. Acta 504 (2004) 191.

[20] J. Haginaka, Bioseparation 10 (2001) 337.

[21] T. Akiyama, T. Hishiya, H. Asanuma, M. Komiyama, J. Inclu. Phen. Macroc. Chem. 41 (2001) 149.

[22] B.R. Hart, K.J. Shea, J. Am. Chem. Soc. 123 (2001) 2072.

[23] A. Rachkov, N. Minoura, J. Chromatogr. A 889 (2000) 111.

[24] V.T. Remcho, Z.J. Tan, Anal. Chem. 71 (1999) 248A.

[25] Y. Watabe, K. Hosoya, N. Tanaka, T. Kubo, T. Kondo, M. Morita, J. Chromatogr. A 1073 (2005) 363.

[26] M. Kempe, K. Mosbach, J. Chromatogr. A 691 (1995) 317.

[27] A.L. Graham, C.A. Carlson, P.L. Edmiston, Anal. Chem. 74 (2002) 458.

[28] K.K. Unger, T.P. Hennessy, M. Huber, M.T.W. Hearn, K. Walhagen, Anal. Chem. 74 (2002) 200A.

[29] M. Bedair, Z. El Rassi, Electrophoresis 25 (2004) 4110.

[30] Á. Végvári, S. Hjertén, Electrophoresis 24 (2003) 3815. 
[31] C.C. Lin, C.Y. Liu, Electrophoresis 25 (2004) 3216.

[32] S. Subrahmanyam, S.A. Piletsky, E.V. Piletska, B. Chen, R. Day, A.P.F. Turner, Adv. Mater. 12 (2000) 722.

[33] E.V. Piletska, S.A. Piletsky, S. Subrahmanyam, K. Karim, A.P.F. Turner, Polymer 42 (2001) 3603.
[34] A. Ellwanger, P.K. Owens, L. Karlsson, S. Bayoudh, P. Cormack, D. Sherrington, B. Sellergren, J. Chromatogr. A 897 (2000) 317.

[35] S.C. Chuang, C.Y. Chang, C.Y. Liu, J. Chromatogr. A 1044 (2004) 229.

[36] J. Jakes, Czech. J. Phys. B38 (1988) 1305.

[37] R.P. Diez, J.I. Amalvy, J. Mol. Struct.: Theochem. 634 (2003) 187. 